\title{
INVESTIMENTO EM STARTUPS: ALTERNATIVA À POLÍTICA DE
} AUSTERIDADE

\author{
Stéfani Clara da Silva Bezerra* \\ Juliana Diógenes Pinheiro ${ }^{* *}$
}

\section{RESUMO}

A política de austeridade não tem se mostrado uma medida viável à retomada do desenvolvimento econômico. Em contrapartida, surgem nesse mesmo cenário, as startups com grande potencial de gerar lucros expressivos e fomentar o Produto Interno Bruto nacional. Consideradas como empresas versáteis, são empreendimentos inovadores. Para escalonar sua produção ou prestação de serviços e adentrar no mercado, precisam contar com apoio financeiro. A figura do Investidor-anjo surge nesse contexto de patrocínio e consequente obtenção de lucros com a renda gerada por estas, fomentando assim a economia. O investimento nas startups, dessa forma, se mostra como opção viável ao desenvolvimento econômico.

Palavras-chave: Política de austeridade; Crise econômica; Startups; Investidor-anjo; Lei Complementar n. 155/2016.

\section{INVESTMENT IN STARTUPS: ALTERNATIVE TO THE POLITICS OF AUSTERITY}

\begin{abstract}
Austerity policy has not proved to be a viable measure for the resumption of economic development. On the other hand, in this same scenario, start-ups with great potential to generate expressive profits and foster the national Gross Domestic Product. Considered as versatile companies, they are innovative endeavors. To scale up their production or service and enter the market, they need financial support. The figure of the angel investor appears in this context of sponsorship and consequent profitability with the income generated by them, thus fostering the economy. Investment in startups, thus, proves to be a viable option for economic development.
\end{abstract}

Keywords: Austerity policy; Economic crisis; Startups; Angel investor; Complementary Law n. $155 / 2016$.

\section{INTRODUÇÃO}

\footnotetext{
* Mestranda em Direito e Desenvolvimento pelo Centro Universitário Christus (UNICHRISTUS). Bolsista da Fundação Cearense de Apoio ao Desenvolvimento Científico e Tecnológico (FUNCAP). Especialista em Direito Processual Civil pela Faculdade Tecnológica de Palmas (FTP). Bacharel em Direito pela Universidade de Fortaleza (UNIFOR). E-mail: <stefani.scb@gmail.com>.

** Mestranda em Direito e Desenvolvimento pelo Centro Universitário Christus (UNICHRISTUS). Especialista em Direito Previdenciário pela UNIFOR. Especialista em Administração Hospitalar pela FGV. Graduada em Direito pela FBUNI. Graduada em Odontologia pela UNIFOR. E-mail: <jdpinheiro45@hotmail.com>.
} 
O cenário de crise econômica vem se alastrando por diversos países ao redor do mundo. A principal medida adotada é a política de austeridade, traduzida como uma prática de cortes de gastos públicos e erosão de direitos sociais.

Em contrapartida, as inovações tecnológicas começam a ganhar expressividade na constituição do Produto Interno Bruto (PIB) dos mais variados países, independentemente da sua imersão na crise econômica.

Dentre essas plataformas de tecnologia, encontram-se as startups. Criadas com a finalidade de desenvolver uma ideia a baixo custo e que seja possível a sua replicação. Podese citar como principais características: proposta inovadora para apresentar ao mercado, modelo de negócio escalável, desenvolvida em base tecnológica, baixo custo e a possibilidade de ser apresentada ao mercado com uma ideia com potencial de se transformar em negócio (BRASIL ECONÔMICO, 2017).

Apesar do risco inicial, as startups são modelos que melhor se adequam ao momento de recessão vivenciado pelos países em decorrência da instituição da política de austeridade (defendida por muitos como a melhor alternativa). Entretanto, como aumentar a participação destas no PIB nacional diante das limitações proferidas pela Emenda Constitucional n. 95 de 2016 (Emenda do Teto dos Gastos)?

Tratando-se de iniciativa privada, como seria possível o incentivo à criação e desenvolvimento das startups sem o comprometimento das receitas públicas? Nesse momento de recessão, seria possível o Estado "investir" em infraestrutura? A concessão de benefícios fiscais poderia ser um mecanismo de fomento?

Numa visão ampla sobre a possibilidade da utilização da economia comportamental associada às startups é necessário conhecer os conceitos pertinentes às áreas do conhecimento que estarão interligadas na tentativa de viabilizar a concretização e efetivação do incentivo à criação e desenvolvimento destas.

O presente artigo aborda qualitativamente o assunto, através de pesquisa bibliográfica e análise da legislação, demonstrando, assim, a relevância do apoio e investimento nos empreendimentos denominados startups para fins de recuperação econômica diante do cenário de crise que assola o Brasil.

\section{POLÍTICA DA AUSTERIDADE}


Austeridade implica rigidez, rigor, disciplina, obediência às regras etc. Importando o seu conceito para o âmbito econômico, tem-se que uma política de austeridade traduzida pelo controle de gastos supérfluos (SIGNIFICADOS BR, [201?]).

Em um primeiro momento, partindo-se do seu significado propriamente dito, a austeridade pode ser vista como algo benéfico. Todavia, como medida imposta pelo Fundo Monetário Internacional (FMI) aos países devedores, essa política tem fortes efeitos colaterais (negativos) tanto na economia como na sociedade.

A austeridade deveria proporcionar reformas com a finalidade de recuperar e estabilizar os mercados através de medidas de flexibilização tanto dos direitos trabalhistas quanto sociais, de modo a facilitar a criação de empregos e, assim, aumentar a competitividade. Porém, ao contrário do que pretende, "os conteúdos apresentados insistem [...] na erosão dos direitos sociais e laborais [tidos como] barreiras a [serem eliminadas] no quadro de uma resposta liberal à crise” (FERREIRA, 2012, p. 29).

Essa prática de flexibilização das relações de trabalho e de erosão de direitos sociais crê que o déficit orçamentário dos países deve ser superado com sacrifícios da população em prol do mercado que, por sua vez, é considerado como o "bote salva-vidas" desse naufrágio financeiro.

Entretanto, esses cortes de gastos públicos podem, também, trazer implicações mais severas à sociedade, qual seja, aumentar o abismo da desigualdade social. Para Amartya Sen (2010), o comedimento financeiro seria uma alternativa viável, ainda que com suas exigências severas de contenção de custos. Porém, para que cumpra com sua finalidade de real recuperação econômica, suas demandas devem observar os objetivos globais da política pública e evitar, assim, a erosão dos direitos sociais que, por sua vez, são a base do Estado de Bem-Estar Social que tenta resguardar o equilíbrio social.

John Rawls (2008, p. 100) acredita que as desigualdades sociais e econômicas não só podem como devem existir, todavia precisam proporcionar "o máximo benefício esperado para os menos favorecidos [e devem ser] vinculadas a cargos e posições abertos a todos em condições de igualdade equitativa de oportunidades".

Ainda que política de austeridade tenha como ponto central a contenção de gastos supérfluos, não se pode admitir uma erosão dos direitos sociais em uma sociedade resguardada por um Estado Social. É nesse sentido que se pode admitir o afastamento do 
Estado como gestor da economia, limitando-se ao papel de expectador "ativo", auxiliando o desenvolvimento da iniciativa privada com a concessão de benefícios fiscais.

A política de austeridade deve estar atrelada ao gasto "consciente", isto é, à destinação qualitativa dos recursos públicos, a fim de alavancar a economia, ao invés de perecer em um ciclo vicioso de recessão.

Pode-se considerar como investimento "consciente" as verbas e/ou incentivos concedidos à criação e desenvolvimento de tecnologia, mais especificamente àquelas voltadas ao e-commerce, conhecidas como startups.

No Brasil, uma especificidade deve ser ressaltada: a Emenda Constitucional n. 95 de 2016 que trata do congelamento dos gastos públicos e que pode ser considerada um forte obstáculo ao incentivo de desenvolvimento tecnológico no país. O que pode ser visualizado, mais especificamente, nas alterações promovidas ao art. 109, §2º II, da EC 95/2016:

\footnotetext{
Art. 109. No caso de descumprimento de limite individualizado, aplicam-se, até o final do exercício de retorno das despesas aos respectivos limites, ao Poder Executivo ou a órgão elencado nos incisos II a V do caput do art. 107 deste Ato das Disposições Constitucionais Transitórias que o descumpriu, sem prejuízo de outras medidas, as seguintes vedações: [...]

$\S 2^{\circ}$ Adicionalmente ao disposto no caput, no caso de descumprimento do limite de que trata o inciso I do caput do art. 107 deste Ato das Disposições Constitucionais Transitórias, ficam vedadas: [...]

II - a concessão ou a ampliação de incentivo ou benefício de natureza tributária. [...] (BRASIL, 2016, online).
}

A política de austeridade pode não ser a medida mais viável para combater o déficit econômico, haja vista não fomentar o desenvolvimento das iniciativas privadas e deixar de observar os objetivos gerais da política pública, dando margem a um ciclo vicioso de recessão.

Atrelada a esta política, o Brasil, tratou de aprovar a Emenda Constitucional n. 95 de 2016 que congela gastos públicos e, consoante visto pelo dispositivo acima, também torna impraticável a concessão de incentivos às inovações tecnológicas o que, por sua vez, pode ir de encontro à possibilidade de investimento na criação das empresas de e-commerce (as startups) e inviabilizar, portanto, a chance da economia brasileira abandonar o déficit orçamentário que assola o país.

\section{STARTUPS: RELAÇÃO COM A ECONOMIA}


As Startups são criadas com a finalidade de desenvolver uma ideia a baixo custo e que seja possível a sua replicação. Pode-se citar como principais características: proposta inovadora para apresentar ao mercado, modelo de negócio escalável, desenvolvida em base tecnológica, baixo custo e a possibilidade de ser apresentada ao mercado com uma ideia com potencial de se transformar em negócio (BRASIL ECONÔMICO, 2017).

Para Eric Ries (2012, p. 24), a startup "é uma instituição humana projetada para criar novos produtos e serviços sob condições de extrema incerteza", que tem na inovação (tecnológica, de produto, serviço, processo ou modelo de negócio) o ponto central de suas operações. Em razão da possibilidade dessas ideias se tornarem escaláveis, ou seja, replicáveis, as startups possuem uma forte disposição para um crescimento rápido.

Dentre as suas características, pode-se dar ênfase a elementos específicos:

[...] iii. Possui significativo controle de gastos e custos. Por meio de uma prática que se cunhou como bootstrapping [...], as startups procuram utilizar ao máximo as capacidades individuais e complementares de cada fundador para diminuir seus custos, focando os investimentos principalmente no desenvolvimento de seu produto e/ou serviço principal.

iv. Seu serviço ou produto é operacionalizado por meio de um produto mínimo viável. Ainda sob a lógica de bootstrapping, os fundadores focam seus investimentos no desenvolvimento de um produto e/ou serviço extremamente rudimentar e simples, apenas para que seja possível verificar se realmente existe demanda e para manter os custos iniciais da startup baixos. [...]

v. O produto ou ideia explorado é escalável. Pela mesma lógica de manutenção baixa dos custos, o produto e/ou serviço geralmente é escalável (facilmente expandido para outros mercados e em diferentes níveis de capilaridade e distribuição), apesar de existirem exceções [...]. A ideia é alcançar uma economia de escala por meio da replicação de um mesmo produto para inúmeros clientes. [...] (FEIGELSON; NYB $\varnothing ;$ FONSECA, 2018, p. 25).

Esses elementos são responsáveis, em grande parte, por fazer com que as startups gerem grandes lucros em pequeno intervalo de tempo, de modo que esse modelo de negócio tem se apresentado como um dos principais componentes do PIB (Produto Interno Bruto) nacional, contribuindo, assim, para alavancar a economia brasileira.

No Brasil, as startups vêm movimentando cerca de R \$ 2 bilhões ao ano, representando $0,03 \%$ do PIB. A meta de crescimento, estimada pela Associação Brasileira de Startups (ABStartups), é que esta margem aumente para 5\% até 2035 (PORTAL CONTÁBIL SC, 2015).

O Produto Interno Bruto - PIB é um dos indicadores econômicos utilizados para se aferir o nível de desenvolvimento de um país. Todavia, nas considerações feitas por Amartya Sen (2010, p. 35), “o papel da renda e da riqueza - ainda que seja importantíssimo, 
juntamente com outras influências - tem de ser integrado a um quadro mais amplo e completo de êxito e privação.”.

Um PIB alto pode implicar o crescimento econômico, criação e expansão das empresas, levando a um aumento no número de empregos, bem como da competitividade no mercado exterior e redução da inflação, o que compatibiliza o conceito de desenvolvimento traduzido, nas considerações de Amartya Sen, pelo aproveitamento e incentivo das capacidades humanas.

Ademais, cumpre salientar que não pode persistir um "critério" único e preciso de desenvolvimento, segundo o qual as diversas experiências de desenvolvimento possam ser sempre comparadas e classificadas (SEN, 2010). Nesse sentido, o PIB não pode ser considerado como único indicador econômico capaz de aferir o nível de crescimento nacional.

Por outro lado, é preciso ressaltar que as startups, apesar de promover um rápido e vultuoso retorno do capital investido, são empreendimentos de alto risco o que pode levar o investidor a selecionar melhor o projeto que receberá seu investimento, bem como a necessidade do Estado atuar viabilizando a criação e desenvolvimento do empreendimento através de incentivos fiscais.

Outrossim, ainda que se trate de investimento de risco, percebe-se que este não é assumido na sua integralidade pelo Estado, que cuida apenas da contrapartida tributária como fomento e incentivo, mas sim pelo particular, que injeta recursos próprios, aguardando o retorno do investimento. Logo, importa salientar que tal prática se mostra compatível com o cenário econômico nacional, haja vista não requerer do ente estatal volumosos recursos.

Como as startups almejam um escalonamento de venda de produtos e/ou serviços, por vezes, o capital inicial investido por seus fundadores se mostra como insuficiente, precisando estas, por ventura, buscarem investidores (pode-se suscitar a figura do investidor-anjo nesse contexto) para patrocinar esse processo de início de atividades ou do próprio plano de expansão (FEIGELSON; NYB $\varnothing$; FONSECA, 2018).

Apesar da startup se apresentar como um modelo disruptivo de negócio, é uma empresa como outra qualquer, não estando, portanto, isenta de responsabilidades jurídicas. Ocorre que, por vezes, o gerenciamento destas, em razão da natureza dinâmica dos empreendedores contemporâneos, pode se dar alheio às questões jurídicas, o que pode levar à falência do empreendimento logo no início de sua constituição. Segundo Bruno Feigelson, Erik Fontenele Nyb $\varnothing$ e Victor Cabral Fonseca (2018, p. 36), "isso se deve ao fato de que 
frequentemente tais questões estarem associadas aos excessos de burocracia e aos modelos obsoletos de gestão característicos do Brasil”. Daí a necessidade da contrapartida estatal para viabilizar, por meio da extrafiscalidade, ambiente propício ao desenvolvimento inicial das startups.

\subsection{Extrafiscalidade e a economia comportamental}

De maneira clássica, a relação do tributo com a finalidade da sua arrecadação possibilita classifica-lo em: fiscais e extrafiscais. Apesar de o Estado brasileiro apresentar a tributação como fonte principal de financiamento, os tributos não devem ser utilizados somente com o fito arrecadatório. Existem outras finalidades dos tributos que podem ser utilizadas pelo ente estatal, inclusive, de maneira positiva no incentivo de algumas atividades econômicas. Desta forma o tributo passa ter uma função denominada de extrafiscalidade.

A estipulação de tributos pelo Estado consiste numa ferramenta fundamental tanto para incentivar como para inibir determinados comportamentos. Segundo André Elali (2007), a tributação surge para o ente estatal como instrumento de fomento ao desenvolvimento nacional, onde, por intermédio das normas tributárias, este poderá e deverá induzir os agentes econômicos a praticar determinados atos, tidos como desejáveis na concretização da ordem econômica proposta pela Constituição Federal.

No que diz respeito à intervenção na economia através da arrecadação, pode-se citar a aplicação de alíquotas progressivas, concessão de isenção fiscal, benefícios fiscais, imunidades tributárias. Ou seja, mecanismos que o Estado pode usar para incentivar o desenvolvimento econômico. Ramon Tomazela Santos (2015, p. 341) afirma que

[...] a neutralidade e a eficiência econômica estão relacionadas à promoção do desenvolvimento econômico, que, para ser alcançado, depende de uma adoção eficiente de recursos no mercado, com o menor grau possível de influência ou interferência da lei tributária. [...] sob o ponto de vista econômico, as regras tributárias não devem, em regra, interferir ou afetar o julgamento econômico racional dos contribuintes em suas decisões a respeito da alocação dos fatores de produção [...], salvo se necessário para corrigir imperfeições no mercado, hipótese em que o sistema tributário pode ser utilizado para reparar, anular ou mitigar ineficiências na alocação dos recursos, bem como para compensar outras externalidades que possam afetar a eficiência econômica do mercado.

Tendo em vista que a política de austeridade não tem se demonstrado como um mecanismo hábil à retomada do crescimento econômico e estando o Estado com as "mãos 
atadas" pela EC 95/2016, como seria possível fomentar a criação e desenvolvimento de plataformas tecnológicas voltadas às práticas comerciais?

A Organização das Nações Unidas (ONU) propõe que os países, para fugirem dessa crise econômica generalizada, pensem em alternativas criativas, tais como investimento em infraestrutura de tecnologias (ONU..., 2017). Porém, como fazer isso?

Daí a sugestão que o Estado possibilite, através da função extrafiscal dos tributos, um cenário de desenvolvimento de novos negócios decorrente de inovações tecnológicas, isto é, proporcionar um ambiente favorável à criação dessas empresas de e-commerce.

Inicialmente é preciso suscitar que a função extrafiscal não se limita à simples ideia de inibição ou incentivo de comportamentos, por vezes, ela pode não surtir o efeito esperado. É preciso levar em consideração o aspecto subjetivo do indivíduo e considera-lo além da ótica de homo economicus que apenas avalia custo x benefício. Nas palavras de Hugo de Brito Machado Segundo (2018, p. 648):

Entende-se por homo economicus, como dito, a idealização de um ser humano que
toma decisões com base, apenas, em seu próprio interesse, ou, em outras palavras,
ponderando aquilo que tem a ganhar e perder, diante das diversas opções ou
alternativas possíveis, sem cometer erros de julgamento e sem se deixar levar por
fatores outros que não o dos ônus e bônus econômicos inerentes a cada opção. A
escolha "racional", feita nesses termos, seria a daquele caminho que trouxesse as
menores perdas e os maiores ganhos para o sujeito que decide, presumidamente
sempre preocupado apenas consigo mesmo.

Para o autor, a concepção de homem como um ser egoísta, individual e que sempre persegue os próprios interesses materiais foi uma imagem distorcida pela Economia contemporânea, de modo que, nem sempre ele age como homo economicus, mas também movidos a outros fatores que interferem na sua tomada de decisões (MACHADO SEGUNDO, 2018).

A decisão de investir ou não em uma startup pode não estar exclusivamente ligada a fatores econômicos diretos. Um modelo de investimento que analisa aspectos subjetivos de organização de uma startup é o Investidor Anjo.

O termo "Investidor-Anjo", originalmente Angel Investor ou Business Angel, foi cunhado nos Estados Unidos, no início do século 20, para designar os investidores que bancavam os custos de produção das peças da Broadway, assumindo os riscos e participando de seu retorno financeiro, bem como apoiando na sua execução. $O$ conceito evoluiu para o investimento efetuado por pessoas físicas, normalmente profissionais ou empresários bem sucedidos, em empresas iniciantes (as startups), fornecendo não somente capital financeiro, mas também intelectual, apoiando o empreendedor com sua experiência e conhecimento. Por isso, ficou conhecido como Smart-Money. O Investidor-Anjo recebe, por seu investimento, uma participação 
societária minoritária no negócio, e não assume posição executiva na empresa, mas atua como um conselheiro orientando os empreendedores e participando das decisões estratégicas da empresa, aumentando muito suas chances de sucesso, bem como acelerando seu desenvolvimento (SPINA, 2012, online).

A figura do investidor anjo vai além da aplicação de capital financeiro em uma startup, requer uma participação ativa do investidor que pode estar motivada não apenas pelo retorno econômico em si, mas também pelo exercício do poder de liderança, comprometimento com a ideia desenvolvida e assunção de riscos.

"Ainda que o investimento-anjo opere em valores inferiores aos fundos, sua importância para o mercado é inegável [...] por não ser um investidor exclusivamente financeiro [...] mas por servir como um mentor ou apoio do empreendedor" (FEIGELSON; NYB $\varnothing$; FONSECA, 2018, p. 96). Daí poder se falar em fatores subjetivos que movem o indivíduo a se sub-rogar na figura do Investidor-anjo e participar ativamente de um novo empreendimento que lhe trará não apenas retorno financeiro, mas também reconhecimento no mercado.

A Lei Complementar n. 155 de 2016, modificando alguns dispositivos da LC 123/06, trouxe à legislação a figura do Investidor Anjo, passando, nesse sentido, a contemplar as startups e seu respectivo desenvolvimento no cenário nacional que, como já afirmado, têm-se mostrado um potencial fator para alavancar o PIB brasileiro.

Dentre as modificações, merece atenção os artigos 61-A a 61-D:

Art. 61-A. Para incentivar as atividades de inovação e os investimentos produtivos, a sociedade enquadrada como microempresa ou empresa de pequeno porte, nos termos desta Lei Complementar, poderá admitir o aporte de capital, que não integrará o capital social da empresa.

$\S 1^{\circ}$ As finalidades de fomento a inovação e investimentos produtivos deverão constar do contrato de participação, com vigência não superior a sete anos.

$\S 2^{\circ} \mathrm{O}$ aporte de capital poderá ser realizado por pessoa física ou por pessoa jurídica, denominadas investidor-anjo.

$\S 3^{\circ} \mathrm{A}$ atividade constitutiva do objeto social é exercida unicamente por sócios regulares, em seu nome individual e sob sua exclusiva responsabilidade.

$\S 4^{\circ} \mathrm{O}$ investidor-anjo:

I - não será considerado sócio nem terá qualquer direito a gerência ou voto na administração da empresa;

II - não responderá por qualquer dívida da empresa, inclusive em recuperação judicial, não se aplicando a ele o art. 50 da Lei no 10.406, de 10 de janeiro de 2002 Código Civil;

III - será remunerado por seus aportes, nos termos do contrato de participação, pelo prazo máximo de cinco anos.

$\S 5^{\circ}$ Para fins de enquadramento da sociedade como microempresa ou empresa de pequeno porte, os valores de capital aportado não são considerados receitas da sociedade.

$\S 6^{\circ}$ Ao final de cada período, o investidor-anjo fará jus à remuneração correspondente aos resultados distribuídos, conforme contrato de participação, não 
superior a $50 \%$ (cinquenta por cento) dos lucros da sociedade enquadrada como microempresa ou empresa de pequeno porte.

$\S 7^{\circ} \mathrm{O}$ investidor-anjo somente poderá exercer o direito de resgate depois de decorridos, no mínimo, dois anos do aporte de capital, ou prazo superior estabelecido no contrato de participação, e seus haveres serão pagos na forma do art. 1.031 da Lei no 10.406, de 10 de janeiro de 2002 - Código Civil, não podendo ultrapassar o valor investido devidamente corrigido.

$\S 8^{\circ} \mathrm{O}$ disposto no $\S 7$ o deste artigo não impede a transferência da titularidade do aporte para terceiros.

$\S 9^{\circ}$ A transferência da titularidade do aporte para terceiro alheio à sociedade dependerá do consentimento dos sócios, salvo estipulação contratual expressa em contrário.

§ 10 O Ministério da Fazenda poderá regulamentar a tributação sobre retirada do capital investido.

Art. 61-B. A emissão e a titularidade de aportes especiais não impedem a fruição do Simples Nacional.

Art. 61-C. Caso os sócios decidam pela venda da empresa, o investidor-anjo terá direito de preferência na aquisição, bem como direito de venda conjunta da titularidade do aporte de capital, nos mesmos termos e condições que forem ofertados aos sócios regulares.

Art. 61-D. Os fundos de investimento poderão aportar capital como investidoresanjos em microempresas e empresas de pequeno porte (BRASIL, 2016, online).

A LC 155/16 (BRASIL, 2016) traz algumas peculiaridades com relação a figura do investidor-anjo que, para além da desoneração da carga tributária, dispõe que o empresárioanjo não poderá compor o quadro societário, não dispondo, assim, de poder de voto. Apesar desta medida se mostrar, em um primeiro momento, como prejudicial ao desenvolvimento da atividade empresarial, por outro lado, este se exime da responsabilidade pessoal que poderia lhe ser atribuída no caso de dívidas sociais e consequente desconsideração da personalidade jurídica.

Ademais, a LC 155/16, ainda que tenha provocado alterações na LC n. 123/06, obstaculizou o investimento-anjo ao definir "que toda tributação dos rendimentos do contrato de participação [...] nas startups ficariam sujeitos à regulamentação pela Receita Federal". Ocasião em que, julho de 2017, a Receita, por meio da Instrução Normativa RFB n. 1.719, decidiu que os ganhos decorrentes desse contrato celebrado entre o investidor-anjo e a startup seriam tributados nos mesmos moldes de um investimento feito em renda fixa no momento que fosse resgatado (KNEBEL, 2018, online).

Diante da referida Instrução Normativa, Bruno Feigelson, Erik Fontenele Nyb $\varnothing$ e Victor Cabral Fonseca (2018, p. 135) entendem que essa medida causaria um prejuízo às intenções do Investidor-anjo, pois:

A receita tributou o repasse de resultados aos investidores, o que pouco ocorre no momento em que normalmente o investimento-anjo é operado - pelo simples fato de que, neste ponto de sua existência, geralmente a startup ainda não atingiu o 
breakeaven. O investidor-anjo costuma saber disso e pouco se interessa pelo recebimento de dividendos nesse momento. O resgate também não é o maior objetivo do contrato; é um investimento de risco, e o anjo deve saber que não faz sentido pensar em aportar capital em startup almejando uma retirada atualizada, poucos anos depois. Logo, questiona-se o quanto a tributação resultou inócua.

Levando-se em conta que o investidor-anjo, geralmente, não é detentor de um grande capital financeiro, a regulamentação feita pela Receita Federal acaba desestimulando o "apadrinhamento" das startups por esses indivíduos, inviabilizando, portanto, o desenvolvimento destas e suas respectivas contribuições ao cenário econômico brasileiro.

Segundo estudo feito pela organização Anjos do Brasil (2017, online), após uma simulação do patrocínio de uma startup por um investidor-anjo pelo período de cinco anos, constatou-se, quanto ao recolhimento dos tributos no ato da venda (momento em que o investidor irá receber os lucros provenientes da atividade nos moldes da LC 155/16) que a isenção total do imposto sobre rendimentos e ganho de capital ou a compensação de até 50\% do valor do investimento nos impostos devidos pelo investidor (políticas essas de incentivo fiscal) surte efeitos positivos tanto para a Receita Federal como para a economia brasileira, por ocasião dos empregos gerados.

Ainda que as startups sejam investimentos de alto risco, é possível aumentar a adesão do investidor-anjo no apadrinhamento destas, valendo-se da concessão de incentivos fiscais (exercendo, portanto, a função extrafiscal) e tornando o ambiente mais atrativo aos empreendedores que irão demandar esforços pessoais e financeiros para desenvolver essas empresas de e-commerce.

A economia comportamental apresentada por Daniel Kahneman e Amos Tversky (2018) propõe um estudo voltado ao comportamento humano cuja finalidade, principal, é fazer uma análise dos pontos de conexão do comportamento humano com a economia, levando em consideração a escassez dos recursos. Lembrando que é prudente focar nos aspectos psicológicos determinantes, no processo de estruturação dos julgamentos e nas tomadas de decisão.

Os estudos demonstraram que as pessoas não possuem capacidade cognitiva para decidir tudo de maneira adequada. Diante deste cenário de incerteza e insegurança, os investidores podem ser conduzidos, por pessoas capacitadas, durante o processo de escolha a tomarem decisões adequadas. A possibilidade de utilização da economia comportamental para 
atrair investidor-anjo apresenta-se como uma alternativa de efetivação imediata e simples, de baixo custo e sem imposição ao investidor (KAHNEMAN, 2018).

\section{CONCLUSÃO}

A política de austeridade, por si só, pode não ser uma medida tão maléfica à economia. Todavia, atrelada à Emenda Constitucional n. 95 de 2016 que congela os gastos públicos pode levar a um ciclo vicioso de recessão. Em contrapartida, é possível apresentar as empresas de e-commerce como uma válvula de escape a esse modelo de "arrocho" econômico.

Apresentando-se como um dos principais elementos componentes do Produto Interno Bruto (PIB) brasileiro, as Startups vêm ganhando destaque no cenário nacional, podendo, até mesmo, serem consideradas como "bote salva-vidas" ao déficit orçamentário vivenciado pelo Brasil. De forma que, ainda contribuem ao desenvolvimento socioeconômico, haja vista possuírem grande capacidade de gerar empregos e potencializar o mercado de consumo.

Partindo-se da análise da função extrafiscal dos tributos, é possível induzir ou desestimular determinados comportamentos dos indivíduos, todavia nem sempre os mecanismos de extrafiscalidade surtem o efeito esperado, de modo que é preciso contar, ainda, com os aspectos subjetivos dos contribuintes. É nesse sentido que pode ser trabalhada a figura do Investidor-anjo, não apenas pelo incentivo à prática empreendedora pela concessão de incentivos fiscais, mas possibilitando um ambiente propício (seguro) ao desenvolvimento das plataformas virtuais de e-commerce.

Consideradas atividades de alto risco, as Startups têm se apresentado como solução viável e alternativa à política de austeridade. Entretanto a sobrevivência de muitas delas está diretamente ligada ao incentivo e investimento de capital externo. Daí a importância da figura do investidor-anjo para o sucesso e consequente sobrevivência desse modelo de negócio.

Apesar da LC 155/16 ter inserido no ordenamento jurídico a figura do investidor-anjo, dando-lhe certas "garantias" (ausência de responsabilidade no caso de dívidas sociais, por exemplo), a legislação ainda possui aspectos falhos no que tange ao incentivo fiscal para a iniciativa destes investidores.

Não basta, portanto, a disposição do empreendedor em "apadrinhar" uma startup, tornando-se um Investidor-anjo, é preciso que o Estado, através de políticas fiscais de incentivo, proporcione um ambiente propício para que estas empresas tecnológicas consigam 
se desenvolver e se tornarem rentáveis, tanto para o investidor como para a Receita Federal que terá uma maior arrecadação de tributos.

Como visto por todo o exposto, o investimento na criação e desenvolvimento das Startups pode ser uma alternativa viável à política de austeridade, pois se coaduna com a finalidade estatal, qual seja, criar mecanismos para superar a crise econômica sem que isso comprometa o orçamento público.

O retorno financeiro dessas empresas de e-commerce não se limita a beneficiar o empreendedor particular, mas também de fomentar a criação de empregos e de novos negócios e consequentemente a arrecadação tributária dos entes estatais.

\section{REFERÊNCIAS}

ANJOS DO BRASIL; GRANT THORNTON. O estímulo como ferramenta para o fomento do investimento em startups: o caso do investidor anjo. Disponível em: <http://www.anjosdobrasil.net/uploads/7/9/5/6/7956863/estudo_sobre_estimulo_para_investi mento_em_startups_-_anjos_do_brasil_e_grant_thornton.pdf $>$. Acesso em: 7 dez. 2018.

BRASIL. Emenda Constitucional n. 95, de 15 de dezembro de 2016. Altera o Ato das Disposições Constitucionais Transitórias, para instituir o Novo Regime Fiscal, e dá outras providências. Diário Oficial [da] República Federativa do Brasil. Brasília, DF, 15 dez. 2016. Disponível em: < https://www2.camara.leg.br/legin/fed/emecon/2016/emendaconstitucional-95-15-dezembro2016-784029-publicacaooriginal-151558-pl.html>. Acesso em: 6 dez. 2018.

BRASIL. Constituição (1988). Constituição da República Federativa do Brasil. Disponível em: http://www.planalto.gov.br/ccivil_03/constituicao/constituicao.htm. Acesso em: 31 maio 2019.

BRASIL. Lei Complementar n. 155, de 27 de outubro de 2016. Altera a Lei Complementar $\mathrm{n}^{\mathrm{o}}$ 123, de 14 de dezembro de 2006, para reorganizar e simplificar a metodologia de apuração do imposto devido por optantes pelo Simples Nacional; altera as Leis $\mathrm{n}^{\circ} \mathrm{s} 9.613$, de 3 de março de 1998, 12.512, de 14 de outubro de 2011, e 7.998, de 11 de janeiro de 1990; e revoga dispositivo da Lei $\mathrm{n}^{\circ}$ 8.212, de 24 de julho de 1991. Diário Oficial [da] República

Federativa do Brasil. Brasília, DF, 27 out. 2016. Disponível em: <http://www.planalto.gov.br/ccivil_03/LEIS/LCP/Lcp155.htm>. Acesso em: 6 dez. 2018.

BRASIL ECONÔMICO. Startup: entenda o conceito e sabia como funciona o investimento. Disponível em: < https://economia.ig.com.br/2016-06-30/startup-conceito.html>. Acesso em: 5 dez. 2018.

ELALI, André. "Incentivos fiscais, neutralidade da tributação e desenvolvimento econômico: a questão da redução das desigualdades regionais e sociais.” In: MARTINS, Ives Gandra da 
Silva; ELALI, André; PEIXOTO, Marcelo Magalhães. Incentivos fiscais: questões pontuais nas esferas federal, estadual e municipal. São Paulo: MP Editora, 2007.

FEIGELSON, Bruno; NYB $\varnothing$, Erik Fontenele; FONSECA, Victor Cabral. Direito das Startups. 1. ed. São Paulo: Saraiva Educação, 2018.

KAHNEMAN, Daniel. Rápido e devagar: duas formas de pensar. Tradução de Cássio de Arantes Leite. 1 ed. Rio de Janeiro: Objetiva, 2018.

KNEBEL, Patrícia. Investimento anjo pode ter incentivo tributário. Jornal do comércio [site], 29 jan. 2018. Disponível em: < https://www.jornaldocomercio.com/_conteudo/2018/01/economia/607371-investimento-anjopode-ter-incentivo-tributario.html>. Acesso em: $7 \mathrm{dez} .2018$.

MACHADO SEGUNDO, Hugo de Brito. Ciência do direito tributário, economia comportamental e extrafiscalidade. Revista Brasileira de Políticas Públicas, Brasília, v. 8, n. 2, 2018 p. 639-659. Disponível em: < https://www.publicacoes.uniceub.br/RBPP/article/view/5252>. Acesso em: 6 dez. 2018.

ONU pede fim da austeridade fiscal e ousadia para reequilibrar economia global. ONUBR [site], 15 set. 2017. Disponível em: < https://nacoesunidas.org/onu-pede-fim-da-austeridadefiscal-e-ousadia-para-reequilibrar-economia-global/>. Acesso em: 6 dez. 2018.

PORTAL CONTÁBIL SC [site]. Startups crescem $18 \%$ no País e giram R\$ 2 bilhões anualmente na economia. Florianópolis, SC: Economia Notícias, 2015. Disponível em: < http://portalcontabilsc.com.br/noticias/startups-crescem-18-no-pais-e-giram-r-2-bilhoesanualmente-na-economia/>. Acesso em: 10 jun. 2018.

RAWLS, John. Uma Teoria da Justiça. 3. ed., São Paulo: Martins Fontes, 2008.

RIES, Eric. A startup enxuta. Tradução de Carlos Szlak. Lisboa: Leya, 2012.

SIGNIFICADOS BR [site]. Significado de Austeridade. Disponível em: <https://www.significadosbr.com.br/austeridade>. Acesso em: 5 dez. 2018.

SANTOS, Ramon Tomazela. A progressividade do imposto de renda e os desafios de política fiscal. Direito Tributário Atual, n. 33, São Paulo: Dialética/IBDT, 2015.

SEN, Amartya. Desenvolvimento como liberdade. Tradução de Laura Teixeira Mota. São Paulo: Companhia das Letras, 2000.

SPINA, Cassio. Afinal, o que é Investimento-Anjo? Endeavor Brasil [site], 8 fev. 2012. Disponível em: < https://endeavor.org.br/sem-categoria/afinal-o-que-e-investimento-anjo/>. Acesso em: 6 dez. 2018. 